\title{
Erratum
}

M. Oliver Heydorn*

\section{Erratum to: A National Dividend vs. a Basic Income - Similarities and Differences}

https://doi.org/10.1515/bis-2017-1000

Erratum to: M. Oliver Heydorn, 2015, A National Dividend vs. a Basic Income Similarities and Differences, Basic Income Studies, Vol. 11, Issue 2, DOI: 10.1515/bis-2016-0019.

Correction of Omission: In the previous issue of Basic Income Studies, 11(2), it should have been announced that the Research Note, "A National Dividend vs. a Basic Income - Similarities and Differences,” by M. Oliver Heydorn, was the winner of the 2015 Basic Income Studies Prize, chosen from papers submitted at the 2015 North American Basic Income Guarantee Congress, held in New York City, February 26-March 1, 2015.

*Corresponding author: M. Oliver Heydorn, The Clifford Hugh Douglas Institute for the Study and Promotion of Social Credit, Ancaster, Ontario, Canada, E-mail: olheydorn@yahoo.ca 